\title{
Analysis of drill head designs for dual-reciprocating drilling technique in planetary regoliths
}

\author{
Craig Pitcher ${ }^{\mathrm{a}, *}$, Yang $\mathrm{Gao}^{\mathrm{a}}$ \\ ${ }^{a}$ Surrey Space Centre, University of Surrey, Guildford, GU2 7XH, UK
}

\begin{abstract}
The Dual-Reciprocating Drill (DRD) is a biologically-inspired concept which has shown promise in planetary environments, requiring a lower overhead force than traditional rotary drilling techniques. By using two reciprocating backwards-facing teethed halves to grip the surrounding substrate, it generates a traction force that reduces the required overhead penetration force. Research into DRD has focused on the effects of operational and substrate parameters on performance compared to static penetration, with minimal study of the geometrical parameters which define the drill head. This paper presents the exploration of the effects of drill head design on drilling depth and power consumption. Sixteen variations of the original design were tested in planetary regolith simulants up to depths of $800 \mathrm{~mm}$. The experiments showed relationships between final depth, total drill radius and cone shape, though the teeth design had a negligible effect on performance. These results can be used alongside the previous research to optimise the future design and operation of the DRD. Drill stem bending was seen to cause an increase in drilling speed and depth, leading to the exploration of the mechanics of diagonal drilling. This resulted in the proposal of a fully-integrated system prototype that incorporates both reciprocating and lateral motion mechanisms.
\end{abstract}

Keywords: dual-reciprocating drilling, planetary drilling, mars regolith, slippage

\footnotetext{
*Corresponding author. Address: Surrey Space Centre, University of Surrey, Guildford, GU2 7XH, UK. Tel: +447816 184142.

Email address: c.pitcher@surrey.ac.uk (Craig Pitcher)
} 


\section{Introduction}

Subsurface exploration plays a critical role in furthering our understanding of the solar system by obtaining data that can only be found below the surface and in the search for extraterrestrial life. Examples include the search for biomarkers, found below a $2 \mathrm{~m}$ sterile surface layer of decayed organic molecules (Gao et al, 2005), and the search for water ice in the lunar south pole region, which is likely to exist below a dry layer $60 \mathrm{~cm}$ deep (Mitrofanox, I. et al, 2010). The first missions to drill an extraterrestrial surface, and the only ones to bring back samples to Earth, were the Apollo 15, 16 and 17 missions and the Soviet Union's Luna 16, 20 and 24 landers, which drilled down to depths of $3 \mathrm{~m}$ and $160 \mathrm{~cm}$ respectively (Zacny, 2012). The only other missions that have successfully performed drilling operations are the Curiosity rover (Vaniman et al, 2014) and the Venera 13 and 14 landers (Zacny et al, 2008).

The most common terrestrial drilling techniques are rotary, percussive and rotary-percussive. Past missions such as Apollo and those currently in development, for example ExoMars (Re et al, 2008), use the rotary or rotarypercussive techniques. However, rotary drills require a large overhead force, achieved by using a large mass to increase the weight on bit, while the combined rotary-percussive drills are heavy, power-hungry and complex. Given that the mass constraints on spacecraft are extremely stringent, low-mass solutions are being investigated. For example, the Beagle 2 mole used percussive drilling in a self-penetrating design. The internal hammering mechanism allows the mole to penetrate with no external overhead force, though it is unable to penetrate through rock (Richter et al, 2002). The InSight mission will also use a self-penetrating mole to tether a string of temperature sensors (Weinstein-Weiss and Banerdt, 2013), with a prototype being designed to penetrate to a minimum of $3 \mathrm{~m}$ in regolith Hansen-Goos et al (2014).

By taking inspiration from nature, numerous biomimetic solutions have been proposed in many engineering fields, one of which is the dual-reciprocating drilling (DRD) technique. This takes its inspiration from the ovipositor of the sirex noctilio, or wood wasp, which uses the reciprocating motion of two halves with backwards-facing teeth to drill into wood in order to lay its eggs (Vincent and King, 1995). A traction force is generated in the receding half by the teeth, which engage with and grip the surrounding substrate and resist being pulled upwards. This is converted to an additional compressive force available to the penetrating half, reducing the overhead force needed 
to overcome the required penetration force (Gao et al, 2007a), as shown in Figure 1.

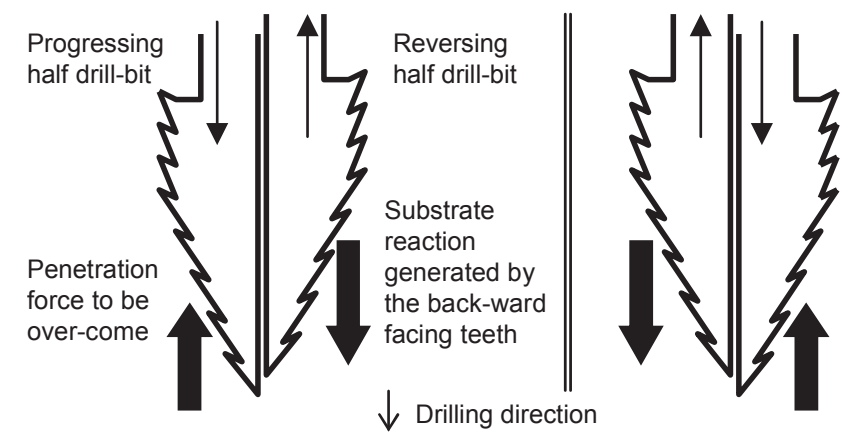

Figure 1: Diagram of the DRD mechanism (Gouache et al, 2011a)

A prototype design was built and tested, and has shown the potential of DRD for drilling low strength rocks, with an energy efficiency comparable to other drilling techniques (Gao et al, 2007b). Experiments were then performed in regolith using a custom-built test bench and new drill head design which studied the effects of the reciprocating frequency and amplitude in different regolith simulants (Gouache et al, 2009, 2011a). This demonstrated the DRD's ability to dig further than static penetration, though high levels of slippage, caused by the receding drill half moving upwards instead of gripping the substrate, were observed. The presence of slight lateral movements of the drill head halves was also found to play a significant role in drilling performance (Gouache et al, 2011b).

The work presented here examines how the drill head and teeth design affects drilling performance. This complements the previous research, which focused on operational parameters, by performing a similar series of experiments in which the geometrical parameters that define the drill head are identified and varied accordingly. Furthermore, in order to show that the DRD has the potential to drill to depths suitable for subsurface planetary exploration, emphasis was placed on examining the drilling performance in terms of final depth reached and power consumption.

\section{Design of Experiment}

\subsection{Definition of the Geometrical Parameters}

The parameters which define the design and operation of the DRD can be placed into three categories: geometrical, operational and substrate. The ge- 
ometrical parameters give the shape of the drill head design, the operational parameters are defined by the technical implementation and experimental set-up and the substrate parameters describe the characteristics of the chosen substrate. Currently, only the effects of the operational and substrate parameters have been studied in detail (Gouache et al, 2011a).

The next logical step is to fully explore the effects of the geometrical parameters by creating a wide range of drill heads, with each having variations from the original design. To do this, five key parameters were defined, shown in Figure 2, each of which could be changed without affecting the others. These are:

- Tooth width, $R_{t}$

- Tooth length, $L_{t}$

- Cylinder width, $R_{\text {int }}$

- Rake angle, $\alpha_{1}$

- Cone half-apex angle, $\alpha$

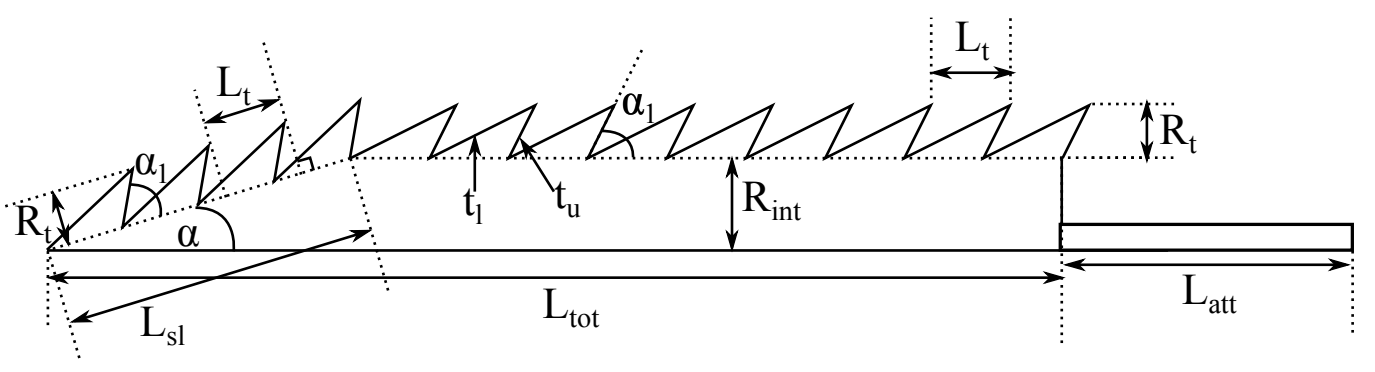

Figure 2: Diagram of the redefined geometrical parameters

The parameters were chosen due to their perceived effect on drilling performance. It is assumed that smaller $R_{t}, R_{\text {int }}$ and $\alpha$ values, creating a smaller, pointier drill, will increase drilling depth. Wide, small teeth with a greater $\alpha_{1}$ will increase the area of contact between the teeth and regolith, which is believed will cause the teeth to better grip the substrate and thus will improve performance.

There are a number of other parameters which will be affected by changing the five key parameters, such as $L_{s l}, t_{l}$ and the number of teeth on the cone 
and cylinder. These are considered relatively unimportant, and are accounted for by keeping the total length of the teeth, $L_{t o t}$, constant. $L_{a t t}$ is an arbitrary length given to the part of the drill which attaches to the drill stem.

\subsection{Design Definition}

In order to produce an efficient and feasible series of experiments, a resolution $\mathrm{V} 2_{V}^{k-1}$ factorial design is used, in which each parameter, $k$, is given a high $(+)$ and low (-) level value. Used in early experimental work, this allows full investigation of the main effects and first-order interactions of each parameter (Montgomery, 2012). This results in sixteen drill head designs with unique parameter level combinations, represented in Table 1.

\begin{tabular}{cccccccccccccccccc}
\hline \multirow{2}{*}{ Parameter } & & $\mathbf{1}$ & $\mathbf{1}$ & $\mathbf{3}$ & $\mathbf{4}$ & $\mathbf{5}$ & $\mathbf{6}$ & $\mathbf{7}$ & $\mathbf{8}$ & $\mathbf{9}$ & $\mathbf{1 0}$ & $\mathbf{1 1}$ & $\mathbf{1 2}$ & $\mathbf{1 3}$ & $\mathbf{1 4}$ & $\mathbf{1 5}$ & $\mathbf{1 6}$ \\
\hline \hline$R_{t}$ & - & + & - & + & - & + & - & + & - & + & - & + & - & + & - & + \\
$L_{t}$ & - & - & + & + & - & - & + & + & - & - & + & + & - & - & + & + \\
$R_{\text {int }}$ & - & - & - & - & + & + & + & + & - & - & - & - & + & + & + & + \\
$\alpha_{1}$ & - & - & - & - & - & - & - & - & + & + & + & + & + & + & + & + \\
$\alpha$ & + & - & - & + & - & + & + & - & - & + & + & - & + & - & - & + \\
\hline
\end{tabular}

Table 1: The parameter levels for each drill head for a $2_{V}^{5-1}$ fractional factorial experiment

The low-level parameters were generally chosen to be similar to those used for the original drill head design, with the high-level parameters being significantly larger. Numerous factors, such as ensuring fitting of the teeth on the cone, greatly restricted the possible $R_{\text {int }}$ and $\alpha$ values. The parameter levels selected are shown in Table2. The drill head designs based upon these parameters are shown in Figure 3 , and were each made with ABS plastic using a MakerBot ${ }^{\mathrm{TM}} 3 \mathrm{D}$ printer.

\subsection{Control of Variables}

The properties of the soil in which the DRD may be required to drill into can vary considerably depending on its type and density (Gouache et al, 2010), and this may affect the performance of the drill. The two substrate types are SSC-1 and SSC-2, whose density is determined by the preparation method: poured or vibrated. The properties of the regolith simulants are given in Table 3. To keep the number of experiments performed at a manageable level, only the substrate type will be changed. This is because, while 


\begin{tabular}{ccc}
\hline Parameters & - Level & + Level \\
\hline \hline$R_{t}(\mathrm{~mm})$ & 3 & 9 \\
$L_{t}(\mathrm{~mm})$ & 7 & 14 \\
$R_{\text {int }}(\mathrm{mm})$ & 7 & 14 \\
$\alpha_{1}\left(^{\circ}\right)$ & 45 & 75 \\
$\alpha\left(^{\circ}\right)$ & 9.59 & 14.48 \\
\hline
\end{tabular}

Table 2: High and low level parameters

changes in the force versus depth profiles due to density are consistent, the profiles for the substrate types are very different, as discussed in (Gouache et al, 2011a). It is believed this variance in profile could cause the drill heads to behave differently.

The regolith is contained in a drum of approximately $600 \mathrm{~mm}$ diameter and filled to its $800 \mathrm{~mm}$ height, thus defining the maximum drilling depth of the experiments. For all experiments, the poured technique was used. The regolith was poured from a bucket into the the drum from approximately $40 \mathrm{~cm}$ above the regolith surface. The densities of poured SSC-1 and SSC-2 are given in Table 3. To avoid compaction over time, each experiment was performed typically within ten minutes of the regolith being prepared. To ensure consistency, the simulant bed was reset after each experiment.

\begin{tabular}{lcc}
\hline Property & SSC-1 & SSC-2 \\
\hline \hline Mineral & Quartz & Garnet \\
Particle Density $\left(\mathrm{kgm}^{-3}\right)$ & 2394 & 3154 \\
Particle Size $(\mu \mathrm{m})$ & $100-1000$ & $30-150$ \\
Particle Shape & Sub-rounded & Sub-Angular \\
Poured Density $\left(\mathrm{kgm}^{-3}\right)$ & 1413 & 1945 \\
Poured Relative Density $(\%)$ & 7.4 & -0.4 \\
Vibrated Density $\left(\mathrm{kgm}^{-3}\right)$ & 1687 & 2344 \\
Vibrated Relative Density $(\%)$ & 74 & 71 \\
Internal Angle of Friction $\left(^{\circ}\right)$ & 35 & 41 \\
Cohesion $(\mathrm{kPa})$ & 910 & 1190 \\
\hline
\end{tabular}

Table 3: Properties of the SSC-1 and SSC-2 regolith simulants Gouache et al, 2011a)

As the focus of these experiments is on the geometrical parameters, the 


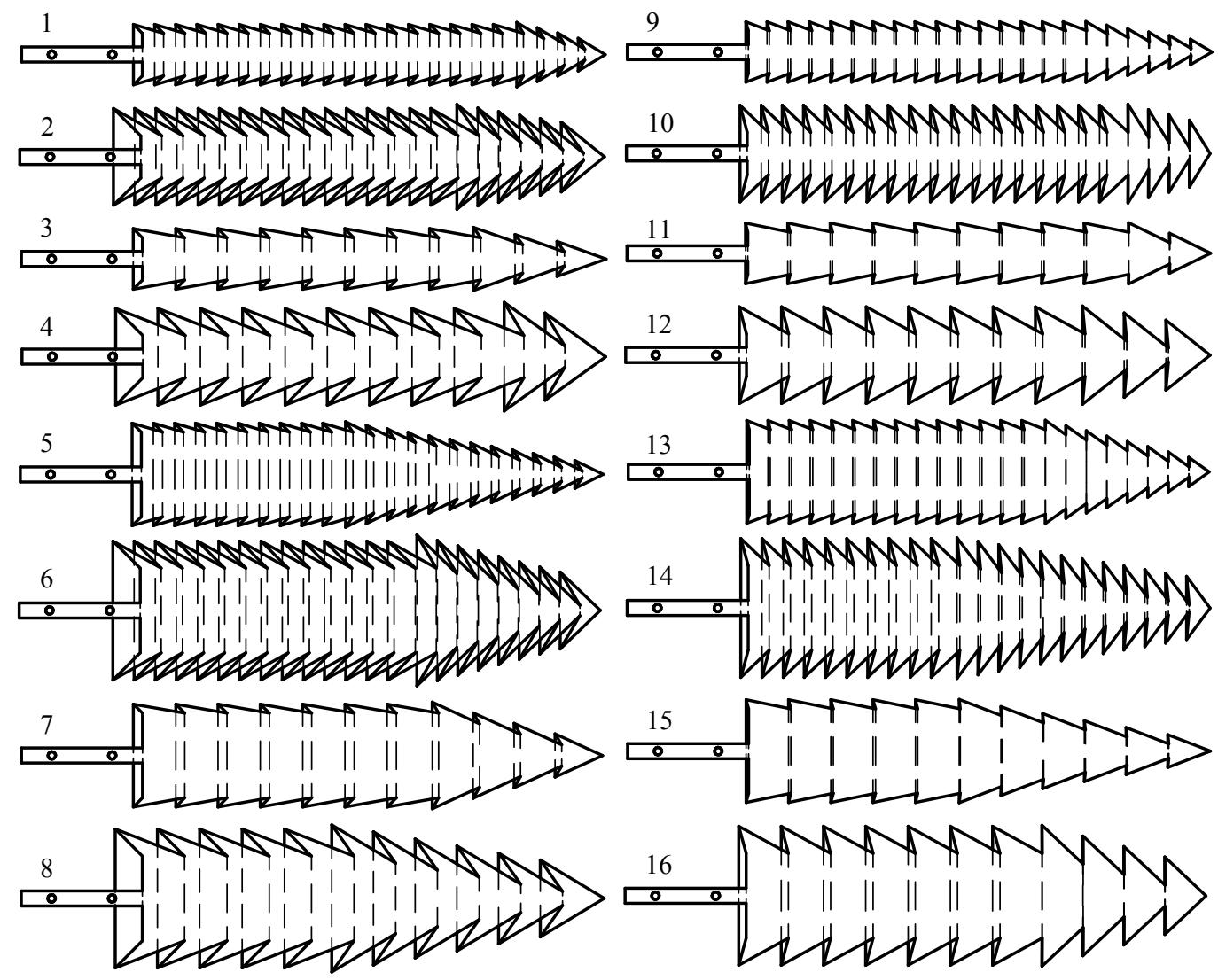

Figure 3: CAD drawings of the drill head designs

overhead force and reciprocation frequency and amplitude will be kept constant, at values similar to those used in previous experiments (Frame, 2012). These are determined by the set-up of the test rig shown in Figure 4, which is explained in detail in (Gouache et al, 2011a). The reciprocation amplitude is set at $\pm 3 \mathrm{~mm}$, i.e. the drill head will travel a distance of $3 \mathrm{~mm}$ from its middle position. The reciprocation frequency is kept constant by using a continuous power supply unit at the motor's nominal voltage of $15 \mathrm{~V}$, which equates to a frequency of approximately $2^{1} /{ }_{3} \mathrm{~Hz}$. The current was allowed to vary from the $0.8 \mathrm{~A}$ required when the test rig ran freely, i.e. not drilling into regolith, to the motor-defined maximum of $4 \mathrm{~A}$, giving a power range of $12-60 \mathrm{~W}$. Finally, the overhead force was set at 30N. Slight variations of $\pm 2 \mathrm{~N}$ were seen, likely caused by imperfections in the test rig or rails creating slight friction differences, and were considered small enough to not cause any 
appreciable change to the drilling operation. Most of the original test rig was used, though a new $1 \mathrm{~m}$ long drill stem was designed, consisting of removable segments and an external interlocking mechanism. The maximum drilling depth, defined by the size of the regolith barrel, is $800 \mathrm{~mm}$.

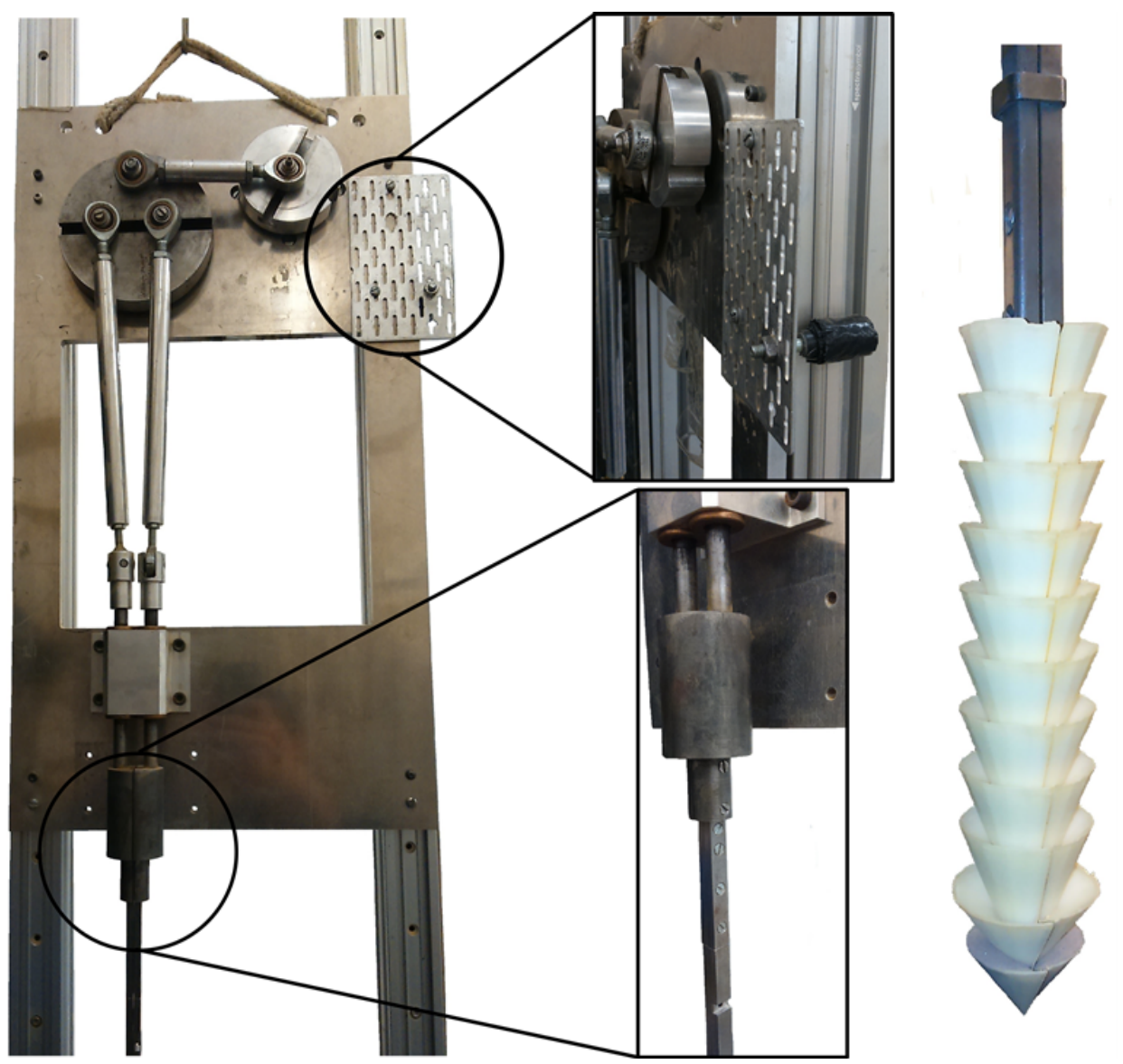

Figure 4: Overview of the test rig, highlighting the displacement measurement system and the connections of the drill stem to the reciprocating mechanism and the drill heads

\subsection{Measured Outputs}

In order to determine the efficiency and performance of the drill heads, three outputs will be recorded and analysed: depth profile, slippage and current. Depth profile will be the easiest indicator of drilling performance, determining depth against time and the final depth reached. This will then 
be used to calculate drilling speed and slippage values. The position of the drill was recorded using a roller attachment, highlighted in Figure 4, which pressed into a membrane potentiometer attached to the guiding rails.

As discussed in Section 1, slippage is caused by the backwards-facing teeth failing to grip the substrate enough to hold the receding drill half in place, which pulls upwards as a result. In this context, slippage is defined as the amount of backwards movement of the receding drill half. No backwards movement would give a value of 0 , while a fully receding drill head gives a value of 1 , and would result in no further penetration. The levels of slippage seen so far in (Gouache et al, 2011a) were very large, with the lowest average slippage values observed being 0.9. Slippage, $s$, is calculated from the depth profile, using the equations:

$s=1-\frac{v_{\text {actual }}}{v_{\max }}=1-\frac{\delta}{\Delta} \quad$ where $\quad v_{\text {actual }}=2 \delta f \quad$ and $\quad v_{\max }=2 \Delta f$

$v_{\max }$ is the drill progression speed if there is no slippage, found using the known reciprocation amplitude, equal to the distance the drill head progresses, $\Delta$, and the reciprocation frequency, $f . v_{\text {actual }}$ is the real speed of the drill, and can be found by differentiation of the depth profile. This can then be used to find the actual progression distance per reciprocation, $\delta$, and consequently the slippage.

These experiments will also examine how the motor current and drilling efficiency is affected by the drill head design and depth, and will be able to determine if the relatively small motor used is able to cope with the drills' power requirements. Though the current can also be used to measure the forces on the drill heads, as discussed in (Gouache et al, 2011a), this method is not used here, due to the forces being measured indirectly and the large variance in values seen. The circuit current was found by measuring the voltage drop across a shunt resistor placed after the motor.

\section{Results \& Analysis}

The drill heads were tested twice in each regolith simulant, with the full experimental procedure taking 1.5 - 2 hours. It was soon noticed that the drill stem was showing bending in some experiments and that this was affecting results, explained in more detail in Section 3.6. Factors such as the long, flexible drill stem, difficulties in judging the correct entry angle and structural 
weakness in the drill heads' stem attachment meant consistently performing runs with no bending was extremely difficult. As a result, there were four different levels of success. The ideal experiments experienced negligible or no bending. A number of experiments showed slight bending of the drill stem, generally of no more than five degrees and often not immediately obvious. Significant bending, in which the stem could be seen to be bending during the experiment, often resulted in damaged or permanently bent drill heads. Failed experiments were created by the drill head snapping or motor jamming before a result could be taken. These drill heads were subsequently reprinted. To counter this, it was required that at least one experiment for each drill head and regolith combination must show minimal to no bending. The total experiments performed, detailing their levels of success, is given in Table 4.

\begin{tabular}{|c|c|c|c|c|c|c|c|c|c|c|c|}
\hline Drill Head & & & $\mathrm{C}-1$ & & & & & $\mathbf{S S C}$ & y-2 & & \\
\hline$\overline{1}$ & $\checkmark$ & $\bar{\checkmark} \checkmark$ & & & & $\checkmark$ & • & - & & 0 & \\
\hline 2 & $\bullet$ & $\checkmark$ & ० & & & $\checkmark$ & $\circ$ & $\bullet$ & $\bullet$ & o & $x$ \\
\hline 3 & $\checkmark$ & $\checkmark$ & & & & $\checkmark$ & $\checkmark$ & & & & \\
\hline 4 & $\checkmark$ & $\bullet$ & $\bullet$ & $\bullet$ & $\circ$ & $\checkmark$ & $\checkmark$ & & & & \\
\hline 5 & $\circ$ & $\checkmark$ & $\circ$ & $\circ$ & & $\checkmark$ & $\checkmark$ & & & & \\
\hline 6 & $\circ$ & $\checkmark$ & $\checkmark$ & & & $\checkmark$ & $\checkmark$ & & & & \\
\hline 7 & $\checkmark$ & $\circ$ & $\times$ & & & $\checkmark$ & $\times$ & & & & \\
\hline 8 & $\circ$ & $\checkmark$ & $\checkmark$ & $x$ & & $\checkmark$ & $\checkmark$ & & & & \\
\hline 9 & $\checkmark$ & $\times$ & $\checkmark$ & & & $\checkmark$ & $\checkmark$ & & & & \\
\hline 10 & $\checkmark$ & $\checkmark$ & & & & $\checkmark$ & $\checkmark$ & & & & \\
\hline 11 & $\checkmark$ & $\times$ & o & & & $\bullet$ & $\checkmark$ & ० & & & \\
\hline 12 & $x$ & $\checkmark$ & $\bullet$ & $\circ$ & & $\bullet$ & $\times$ & $\bullet$ & $\circ$ & $\checkmark$ & ○ \\
\hline 13 & $\checkmark$ & $\circ$ & & & & $\checkmark$ & $\times$ & & & & \\
\hline 14 & ० & $\checkmark$ & $\times$ & & & $\checkmark$ & $\checkmark$ & & & & \\
\hline 15 & $\bullet$ & $\bullet$ & $\checkmark$ & $\circ$ & & ○ & $\checkmark$ & & & & \\
\hline 16 & $\checkmark$ & $\checkmark$ & & & & $\checkmark$ & $\checkmark$ & & & & \\
\hline Total & 48 & & & & & 44 & & & & & \\
\hline
\end{tabular}

$\checkmark$ Successful experiment, minimal bending

- Imperfect experiment with slight bending

- Significant bending, creating anomalous results

$\times$ Failed experiment

Table 4: Table of all experiments performed and the levels of success for each 
The analysis of the results aims to show the depth and power profiles caused by the drill head designs in the two substrates. Given the large number of parameters that define a substrate's properties, it is not possible to create an empirical model which determines the performance in any substrate. As such, the results can be used to complement the previous research, with the aim of determining as best as possible notable relationships between the drill head design and current and depth, and establishing if there are any patterns caused by the influence of the operational and substrate parameters.

\subsection{Typical Depth Profiles}

The experiments gave rise to two typical depth against time curves. It should be noted that the term maximum depth is used to describe the depth as determined by the size of the barrel of regolith. This was given as $760 \mathrm{~mm}$, allowing for a safety factor of $40 \mathrm{~mm}$ between the drill and the boundary of the barrel. This is shown in Figure 5(a), in which after the initial penetration caused by the release of the test rig, the drill progresses until it reaches the $760 \mathrm{~mm}$ limit, at which point the drilling is stopped. The term final depth is given to the point at which a drill is no longer penetrating, or is penetrating at a very slow rate. This is shown in Figure 5(b), in which the depth against time curve, after the initial penetration, follows an inverse exponential trajectory.
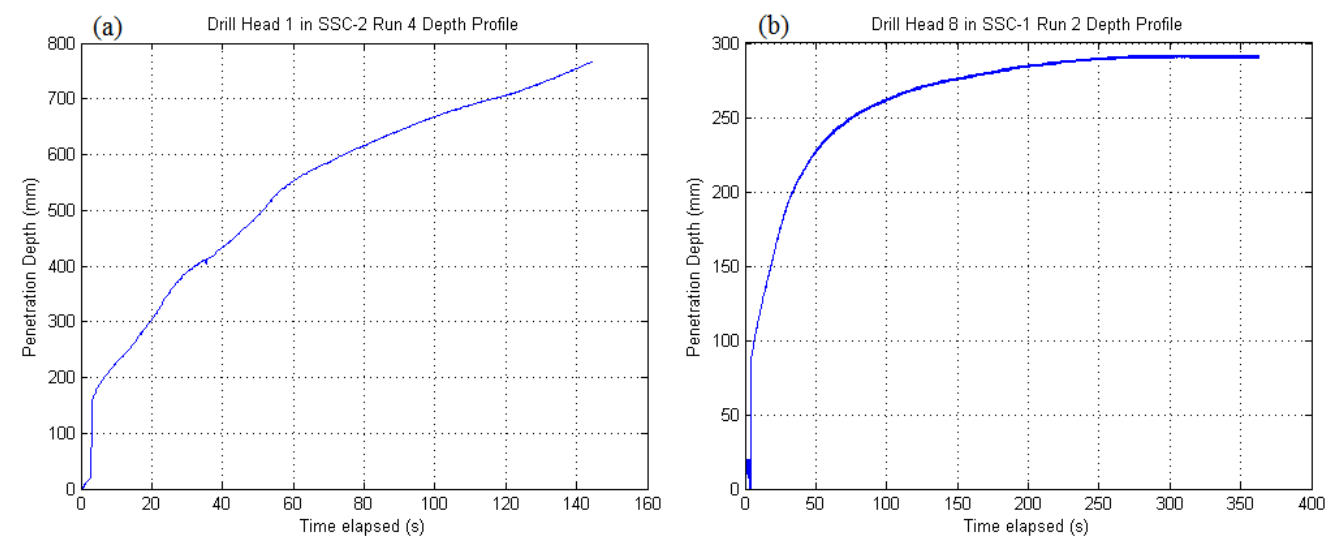

Figure 5: Examples of the two types of depth profile observed

The depth and time values of the two best experiments for each drill headregolith combination and the averages are presented in Figure 6, in which it can be seen that eight and four drill heads reached the maximum depth in SSC-1 and SSC-2 respectively. 


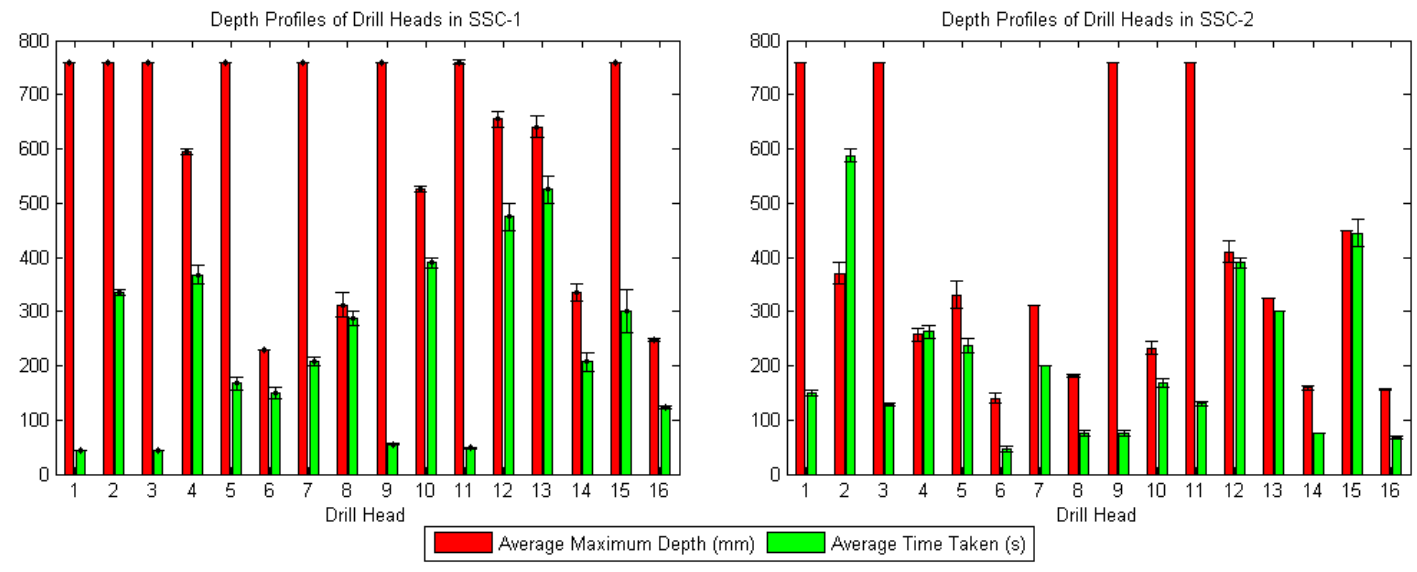

Figure 6: Graphs of the average depth $(\mathrm{mm})$ and time $(\mathrm{s})$ values for all drill heads in SSC-1 and SSC-2, with the values for each successful test given as the error bar points

Each successful run created approximately the same depth profile shape, which can be seen in Figure7. Runs $1-3$ reached different depths at different times, but the profile shapes are very similar. As such, profile 1 can be scaled up to match the profile of run 2 or 3 and vice versa. It can be assumed that the profile of the drills that reached the maximum depth, such as runs 4 and 5 , would follow the same shape. By using this technique, the profile and final depths of all drills which reached the maximum depth were estimated. Given the data points shown in Figure 6 fall within $0-8 \%$ of the average values, the estimated final depths will be given an estimated uncertainty of $8 \%$. These final depth estimates are given in Table 5 .

\begin{tabular}{ccccccccc}
\hline Drill Head & $\mathbf{1}$ & $\mathbf{2}$ & $\mathbf{3}$ & $\mathbf{5}$ & $\mathbf{7}$ & $\mathbf{9}$ & $\mathbf{1 1}$ & $\mathbf{1 5}$ \\
\hline \hline SSC-1 & 1855 & 857 & 2209 & 1125 & 989 & 2045 & 1715 & 802 \\
SSC-2 & 964 & - & 1038 & - & - & 1284 & 1024 & - \\
\hline
\end{tabular}

Table 5: Estimated final depths (in $\mathrm{mm}$ ) of drill heads in SSC-1 and SSC-2, with an uncertainty value of $8 \%$

\subsection{Analysis of Depth Results}

The $2_{V}^{5-1}$ design allows the identification of the most important parameters, found by calculating the estimated effects of the results. The estimated effects graph in Figure 8 shows the importance of the main effects and the 


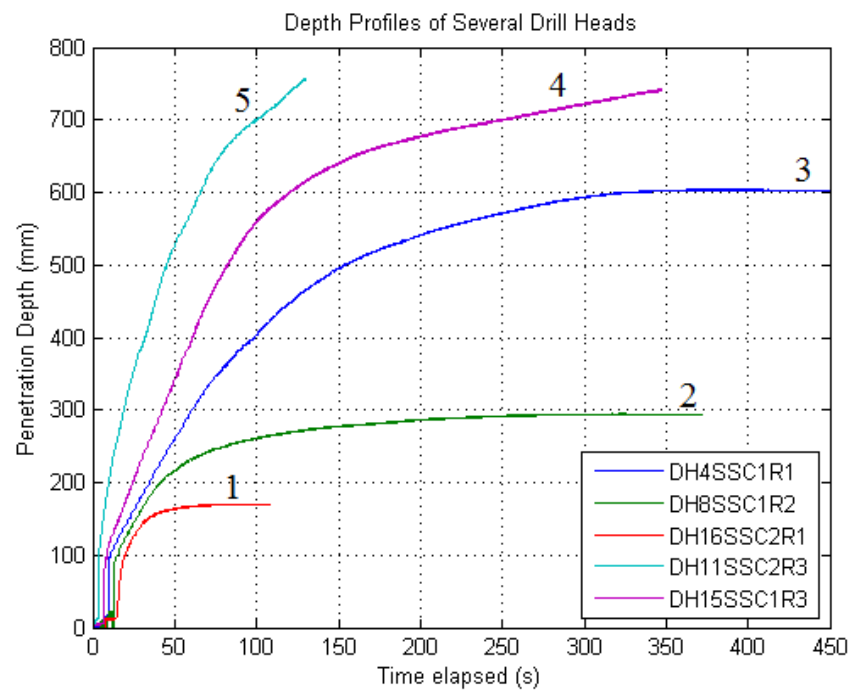

Figure 7: Graph of five depth profiles. Runs $1-3$ show the typical profile when reaching a final depth, runs $4-5$ show an incomplete profile due to reaching the maximum depth

first-order interactions for SSC-1 and SSC-2. The main effect is the change in response produced by changing the level of a key parameter, ignoring the effects of all other parameters. In Figure $8, \mathrm{~A}=R_{t}, \mathrm{~B}=L_{t}, \mathrm{C}=R_{\text {int }}, \mathrm{D}$ $=\alpha_{1}$ and $\mathrm{E}=\alpha$. A first-order interaction occurs when the effect of one parameter is dependent on the level of another parameter. For example, AB refers to the difference in effects of $R_{t}$ at the two $L_{t}$ levels. The greater this difference, the greater the magnitude of the interaction effect.

Generally the results are similar for both simulants. By far the most significant variables are $\mathrm{A}, \mathrm{C}$ and $\mathrm{AC}$. This suggests that, while $R_{t}$ and $R_{\text {int }}$ are important on their own, their combined effect is also significant. Finally, variable $\mathrm{E}$ is also seen to have a small effect, whilst the other variables have very minor effects. It can be assumed that, for these simulants, the length and angle of the teeth have little to no effect on the performance of DRD, while the most critical factors are the radii of the teeth and cylinder, with the shape of the cone also having an effect.

For SSC-2, the importance of the relationship between $R_{t}$ and $R_{\text {int }}$ suggests a non-linear relationship with depth is likely. Given that $R_{t}$ and $R_{\text {int }}$ have similar significance, they will be considered equal factors. By combining these into a single parameter which defines the total radius of the drill, $R_{t o t}$, this gives a parameter with high, low and two medium levels. The rela- 


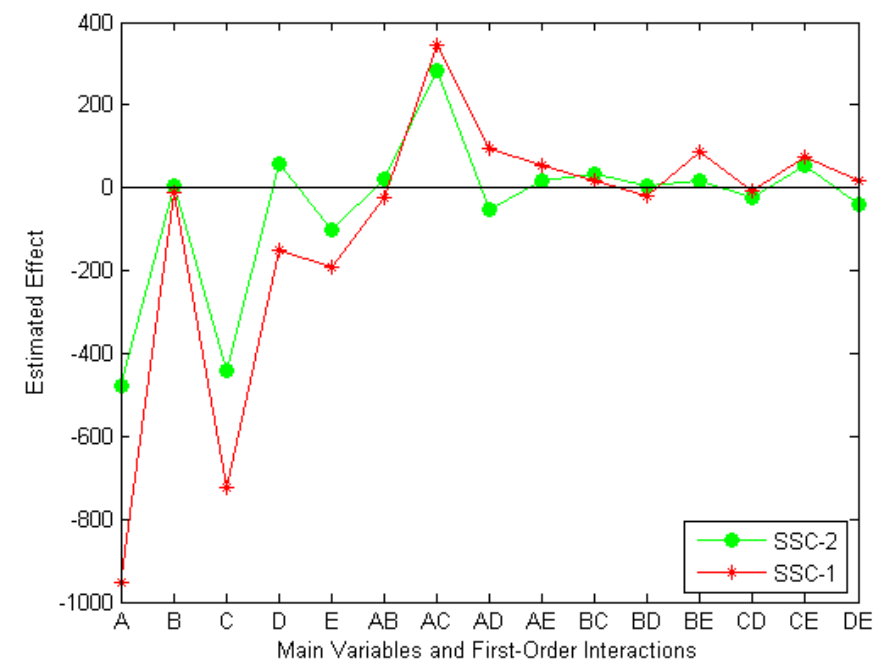

Figure 8: Graph showing the estimated effects for the main variables and first-order interactions

tionship between the $R_{t o t}$ values and depth is given as the scatter points in Figure 9. Immediately it can be seen that the total diameter of the drill has a non-linear relationship, as shown by the red trendline. The data points are also separated into two groups, which correspond to the drills with high and low level cone half-apex angle values. This allows another two trendlines to be formed, one for each data group.

From the trendlines it can be seen that the relationship between the total radius and depth is an inverse power relationship, where the final depth, $D_{f}$, decreases dramatically with increasing $R_{t o t}$, represented by the equation:

$$
D_{f}=c R_{t o t}^{-k}
$$

Where $c$ and $k$ are constants. The cone half-apex angle affects $c$, whereas the change in $k$ is negligible. This gives a final equation for SSC-2 which approximates the final depth relative to $R_{t o t}$ and $\alpha$ :

$$
D_{f}=8500(35-\alpha) R_{t o t}^{-2.27} \quad D_{f} \propto \frac{c \alpha}{R_{t o t}^{-k}}
$$

It must be noted that there are limitations which have to be placed upon this equation. For example, whilst it covers drills with an $R_{\text {tot }}$ between 10 


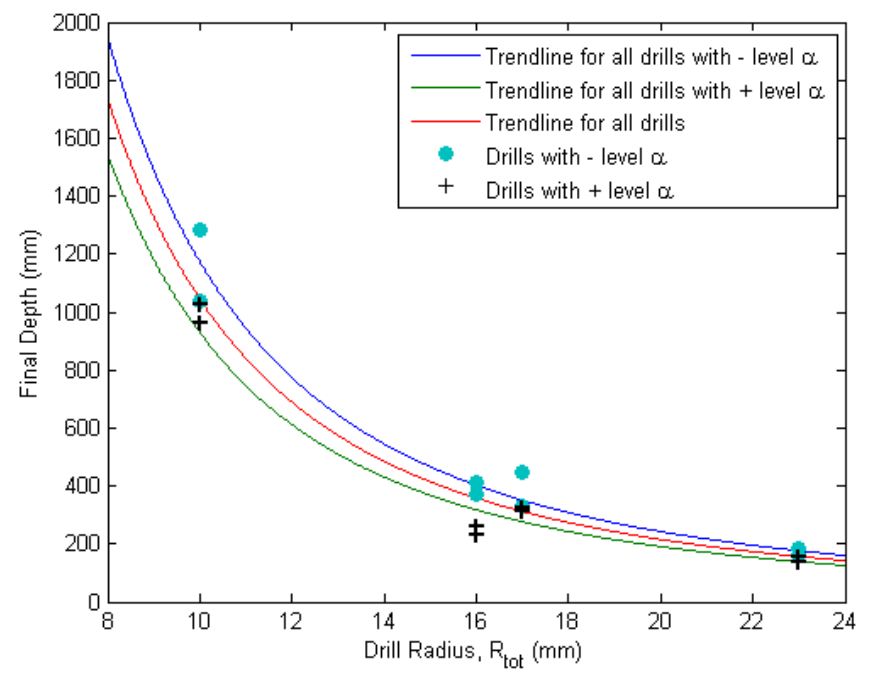

Figure 9: Graph showing the final depths reached for different $R_{t o t}$ values in SSC-2, demonstrating the effects of the total drill radius and cone half-apex angle

and $23 \mathrm{~mm}$ and an $\alpha$ between 10 and $15^{\circ}$, drills with parameters outside these ranges must be extrapolated. Also, neither $R_{\text {tot }}$ nor $\alpha$ can be equal to zero, and $\alpha$ cannot be larger than $90^{\circ}$. Given the inverse power relationship found for $R_{t o t}$, depth estimates dramatically increase as $R_{t o t}$ tends to zero. Similarly, the linear relationship for $\alpha$ results in negative depth values beyond $35^{\circ}$. As such, it should be assumed that the relationship will no longer apply for drill heads with parameters that are close to these values.

As can be seen in Figure 10, the relationship between $R_{t o t}, \alpha$ and depth in SSC-1 follows a similar pattern, which can also be represented by Equation (2). In this case, a very small change in $k$ is also seen, though this can be attributed to estimation inaccuracies, and does not create a significant change in results. This creates a profile which can be approximated as:

$$
D_{f}=11300(21+\alpha) R_{t o t}^{-2.25} \quad D_{f} \propto \frac{c \alpha}{R_{\text {tot }}^{-k}}
$$

The similarity of the profiles suggests that there is a pattern with regards to the geometrical parameters and depth. The constant $c$ is dependent on both the cone half-apex angle and the drilled substrate. However, the equations presented show that total drill diameter and depth have an inverse power relationship of constant value, $k$, of between 2.2 and 2.3. Given the 


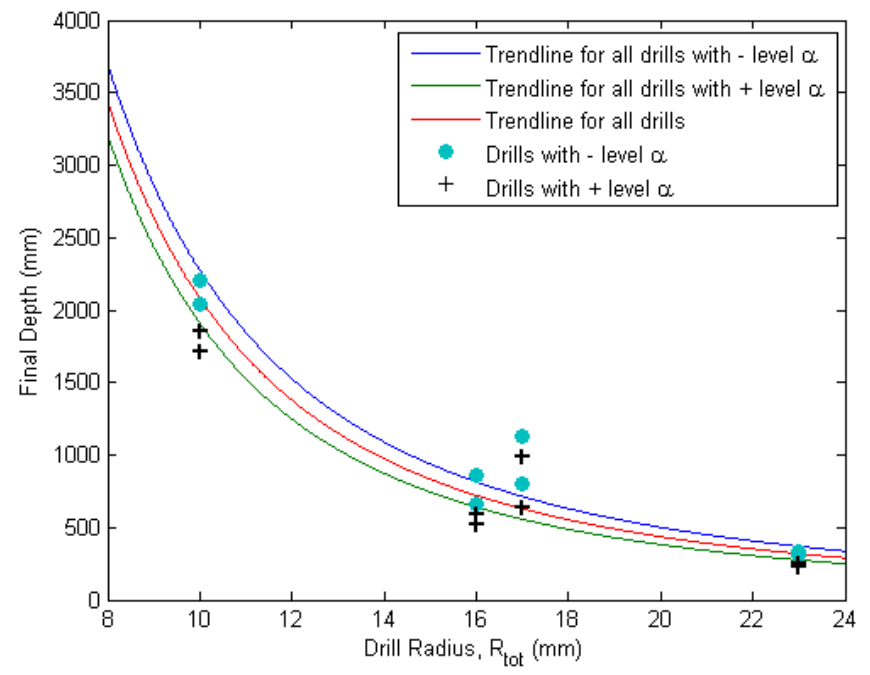

Figure 10: Graph showing the final depth reached for different $R_{t o t}$ values in SSC-1, demonstrating the effects of the total drill radius and cone half-apex angle

number of substrate parameters, an empirical model for all substrates cannot realistically be constructed. However, the results shown indicate that regolith influences the final depth, but has little to no effect on the depth profile for the geometrical parameters.

\subsection{Slippage}

The majority of the slippage profiles follow that shown in Figure 11 in which, after the period of initial penetration where slippage is briefly below zero before rising to a value between 0 and 1 , slippage steadily increases until the drill reaches its final depth. At this point, slippage is equal to 1 , and the drill is unable to progress any further. The slippage curve follows the same curve as the depth profile. Interestingly, in the case of the four thinnest drills in SSC-1, the slippage remains below zero for some time after the initial penetration, as shown in Figure 12. Here the drill is progressing beyond its own capabilities, and is aided by additional natural sinking of the drill through the regolith, caused by a combination of the momentum gathered through the initial penetration, the low density of the regolith and the overhead force. The most critical factor is the density, as this negative slippage is not seen for the same drill in the denser SSC-2. Despite this, the progression of the slippage curve continues as per the other drills, increasing 
steadily until the drill reaches the maximum depth. Beyond 25s, the slippage becomes positive, and the penetration from that point on is caused by the drilling motion only. It must be noted that the spike in slippage at $15 \mathrm{~s}$ was due to a fault in the membrane potentiometer briefly creating false distance measurements.

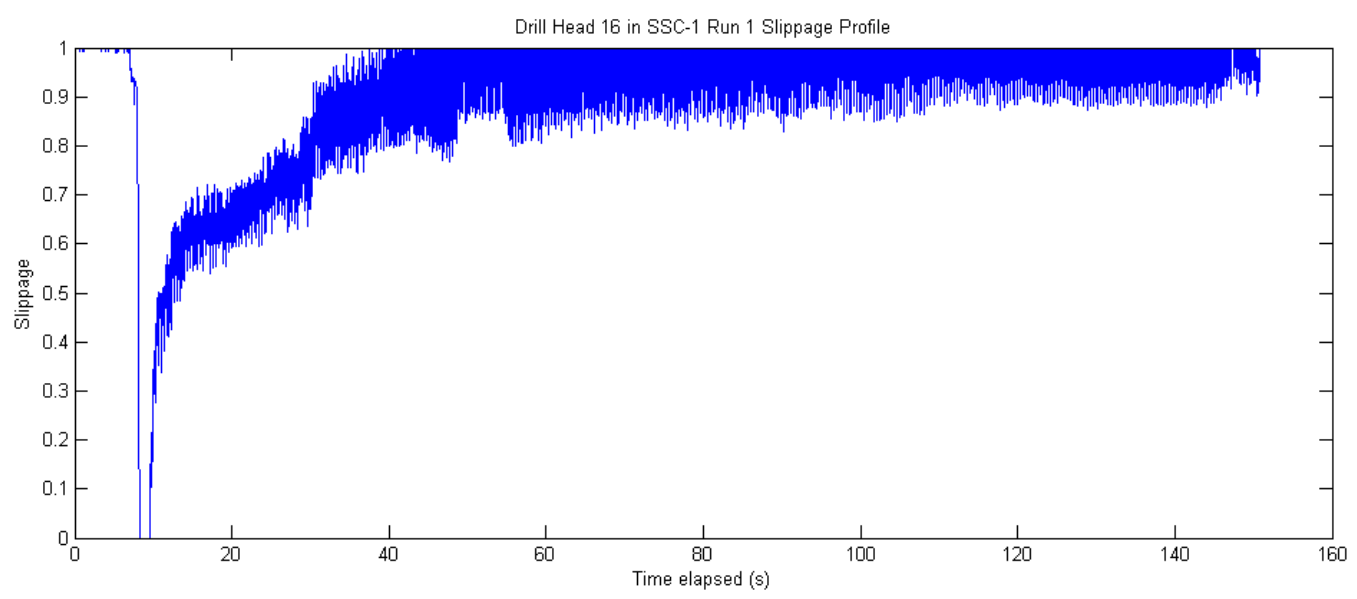

Figure 11: Graph of the slippage profile of drill head 16 in SSC-1

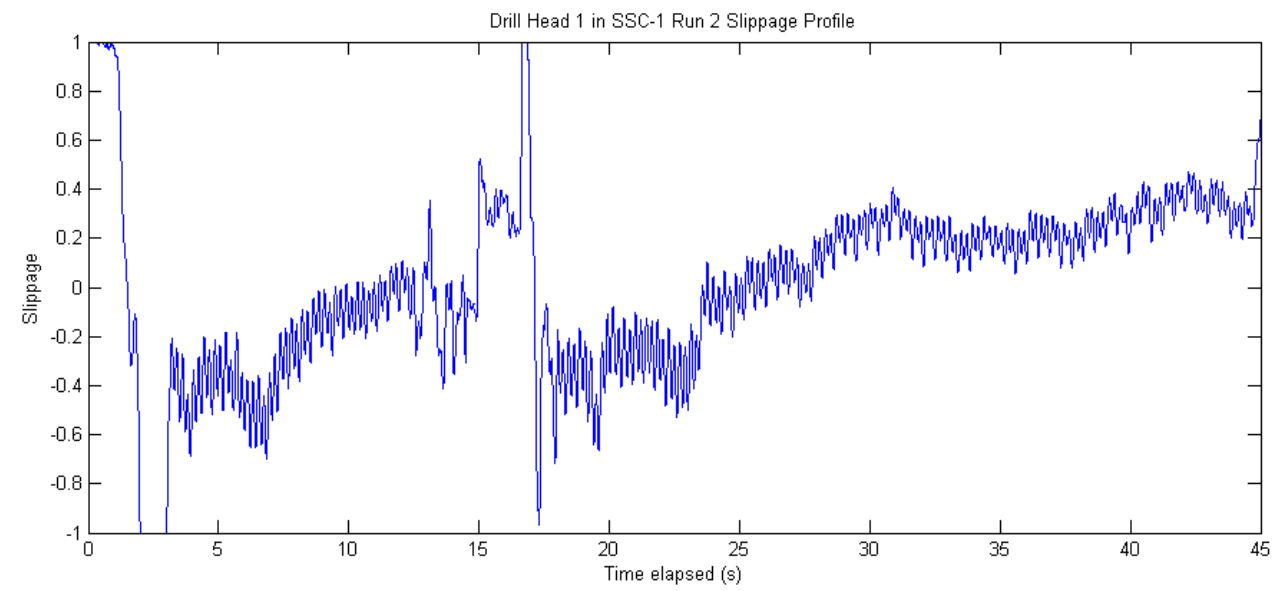

Figure 12: Graph of the slippage profile of drill head 1 in SSC-1 


\subsection{Analysis of Current Results}

The current typically produced a profile such as that shown in Figure 13 . The initial current, i.e. that required to run the test rig mechanisms, was approximately 0.8A. During the experiment, the current tended to increase at the same rate as depth, with a sharp increase during the initial penetration, before slowing and remaining steady at the final depth.

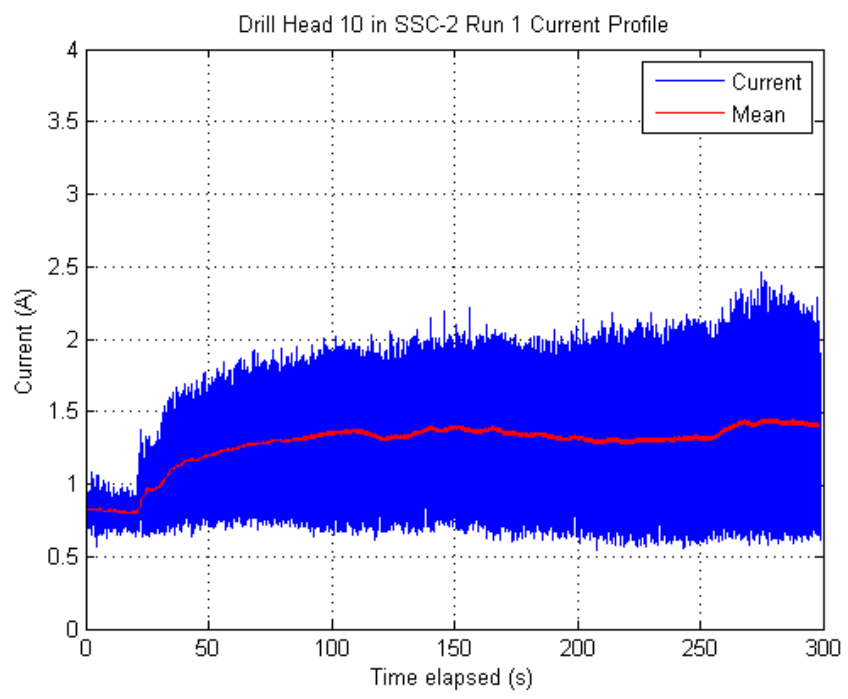

Figure 13: Example of a typical current profile

By taking only the drills that did not reach the maximum depth, a linear relationship between final depth and the average current measured at this depth can be seen, as shown in Figure 14. The power values can be found using the constant voltage supply of $15 \mathrm{~V}$, and as such follow the same trend as the current values. The nature of the external interlocking mechanism led to variations in current readings for the same drill, as the regolith presents a jamming risk. This was particularly noticeable in the SSC-1 regolith due to the particles' larger size, often creating much larger and varying readings, despite being the less-dense material. As such, the SSC-1 results are less reliable, however there is still a clear relationship between depth and current. Had there been no increase in current caused by friction in the external mechanism, the current deviation and increase with depth would have been much smaller. Using the initial current of $0.8 \mathrm{~A}$ as the $x$-intercept, the relationship 
between depth and current is quite similar, with the standard deviation and the $m m A^{-1}$ gradient being larger for SSC-1.
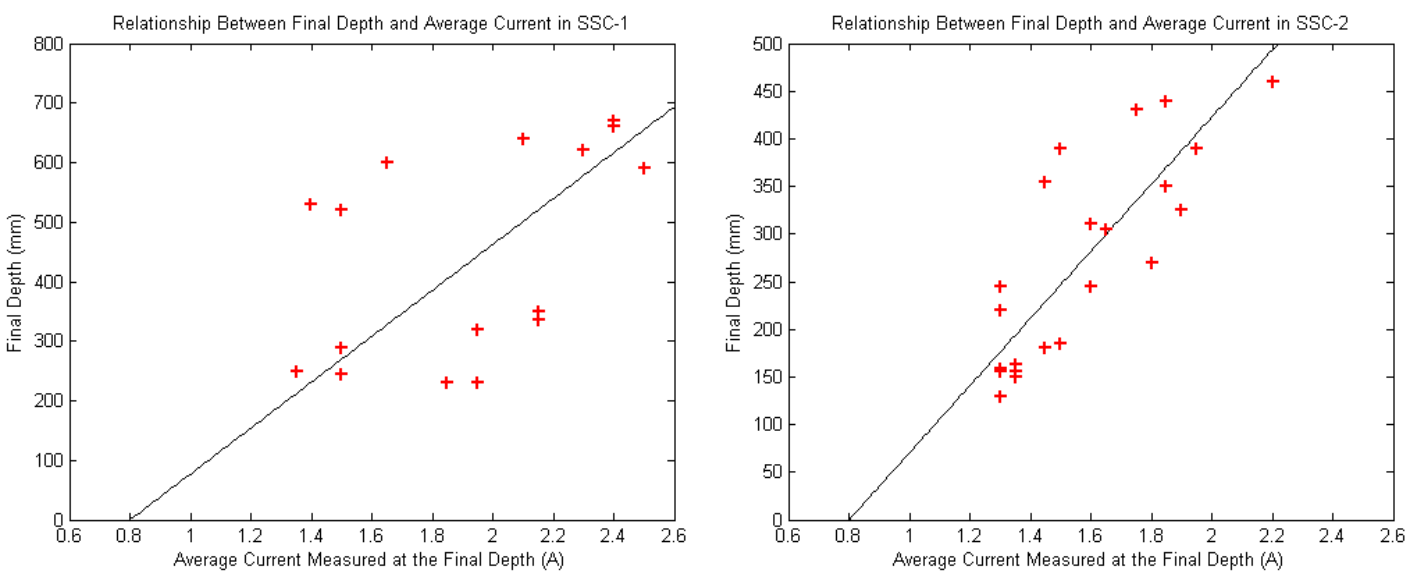

Figure 14: Graphs of the relationship between the final depth and the average current measured in SSC-1 and SSC-2

\subsection{Specific Energy}

Specific energy (SE) is a good representation of drilling efficiency, taking into account drilling power, rate of penetration and drilling area. The rate of penetration increases dramatically as the drill tends towards its final depth. As such, for all drills that reached a final depth, depth and time values were taken at the point the depth profile beings to level out, in the range of 90 $95 \%$ of the final depth (in the case of Figure 5(b), these values are $276 \mathrm{~mm}$ and 125 s respectively). These SE values are given in Figure 15(a). For the drills which reached the maximum depth, the SE required to reach $760 \mathrm{~mm}$ was calculated, and is given in Figure 15(b).

Though the SE values given are estimates, some observations can be made. The SE values given in Figure 15(a) for SSC-1 and SSC-2 follow a very similar pattern to the time taken values given in Figure 6, suggesting a correlation between the two. This is supported by the results in Figure 15(b), as the SSC-2 runs, which took longer to reach the maximum depth, have larger SE values. SE is also likely to have a correlation to final depth reached, given the relationship between power and depth discussed in Section 3.4. This is supported by the four largest drill heads having the lowest $90-95 \% \mathrm{SE}$ values. 

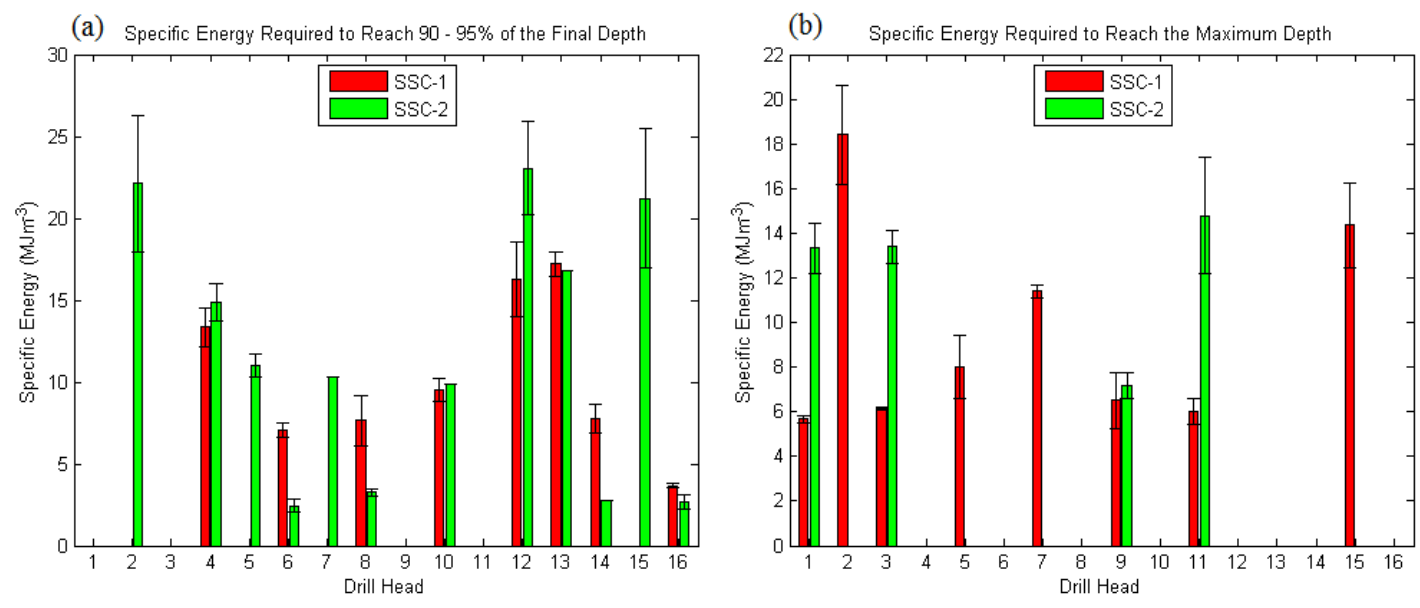

Figure 15: Graphs showing the calculated specific energy values for all drill heads in SSC-1 and SSC-2, with the values for each successful test given as the error bar points

\subsection{Drill Stem Bending}

By far the most common difficulty faced with performing consistent experiments was avoiding bending of the drill stem and/or drill heads. Slight bending did not affect results, with depth profiles indiscernible from straight runs, however significant bending led to completely different depth profiles. As shown in Figure 16, often the penetration profiles would be broadly similar until a certain depth (in this case, up to $500 \mathrm{~mm}$ ). After this, whereas the straight run's penetration would slow and eventually halt, the bent stem would continue progressing at a fairly continuous rate.

It was found that all runs which experienced significant bending of the drill stem showed an increase in final depth and/or a reduction in the time taken to reach the maximum depth. It is observed from the behaviour evidenced by these results that lateral motions caused by the diagonal direction of the drilling create these increases in drilling performance. An explanation for this is the direction the regolith is being compacted, as shown in Figure 17. The principle behind DRD is that the backwards-facing teeth grip into the regolith, which holds the receding half in place, providing an extra compressive force for the penetrating half. However, this relies on the regolith not shearing and remaining in place. In vertical drilling, the receding drill half attempts to move the engaged regolith upwards. Resistance to this is provided by the surrounding regolith, in particular the volume of regolith directly above the engaged regolith. Given that this volume of regolith is 

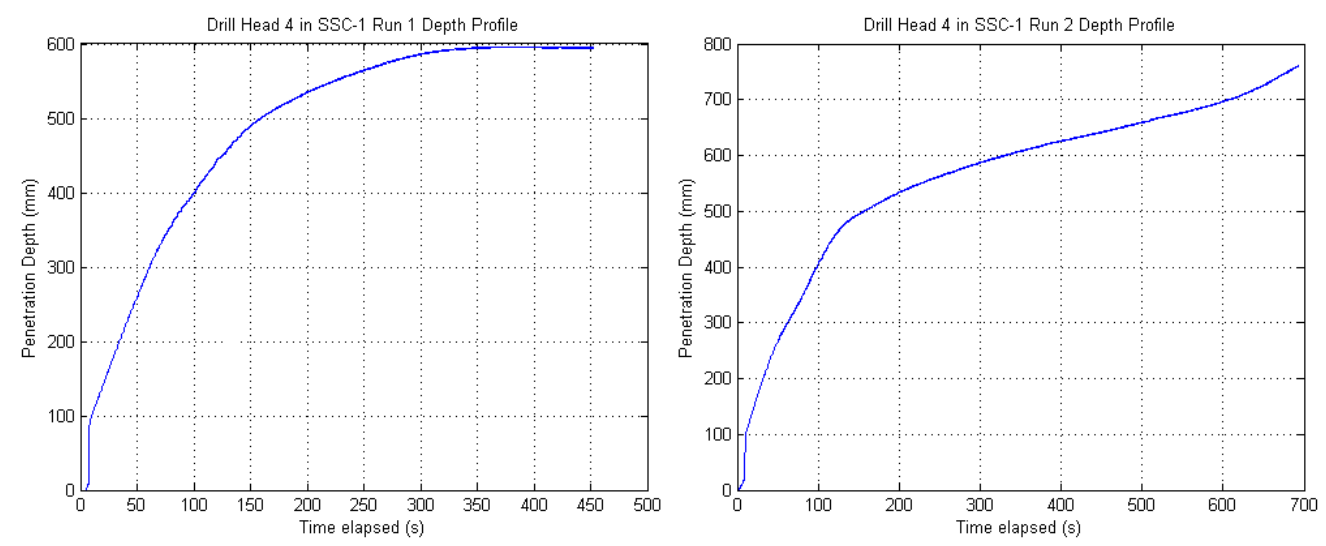

Figure 16: Depth profiles of an experiment with a straight drill stem (a) and bent stem (b)

fairly small and has already been sheared, the overall resistive force is very small, and the drill is able to push the regolith upwards with little resistance. When drilling at an angle, the regolith is being moved both upwards and horizontally. A small amount of resistance is again provided by the regolith directly above the engaged regolith. However, pushing the engaged regolith horizontally into the surrounding regolith is much more difficult, given its much larger volume and the fact that it has not been previously sheared. This means that there is a horizontal resistive force acting alongside the vertical force, making it more difficult for the receding drill head to push the engaged regolith back. This therefore creates a larger tensile force and as a result allows the drill to penetrate further.

Though the extent of how much the drill stem bending was able to improve the drilling performance was not recorded when it occurred, as it often coincided with the drill heads breaking, these results indicate that diagonal drilling is beneficial. The compression mechanics proposed here are likely similar to those caused by the lateral forces discussed in Section 1. Further study will focus upon the progression of the DRD design into a system prototype, including the implementation and analysis of internal actuation mechanisms which allow simultaneous reciprocating and lateral motion. Additionally, deploying a prototype at an angle should be relatively simple, therefore it will also be possible to analyse the benefits of diagonal drilling. 


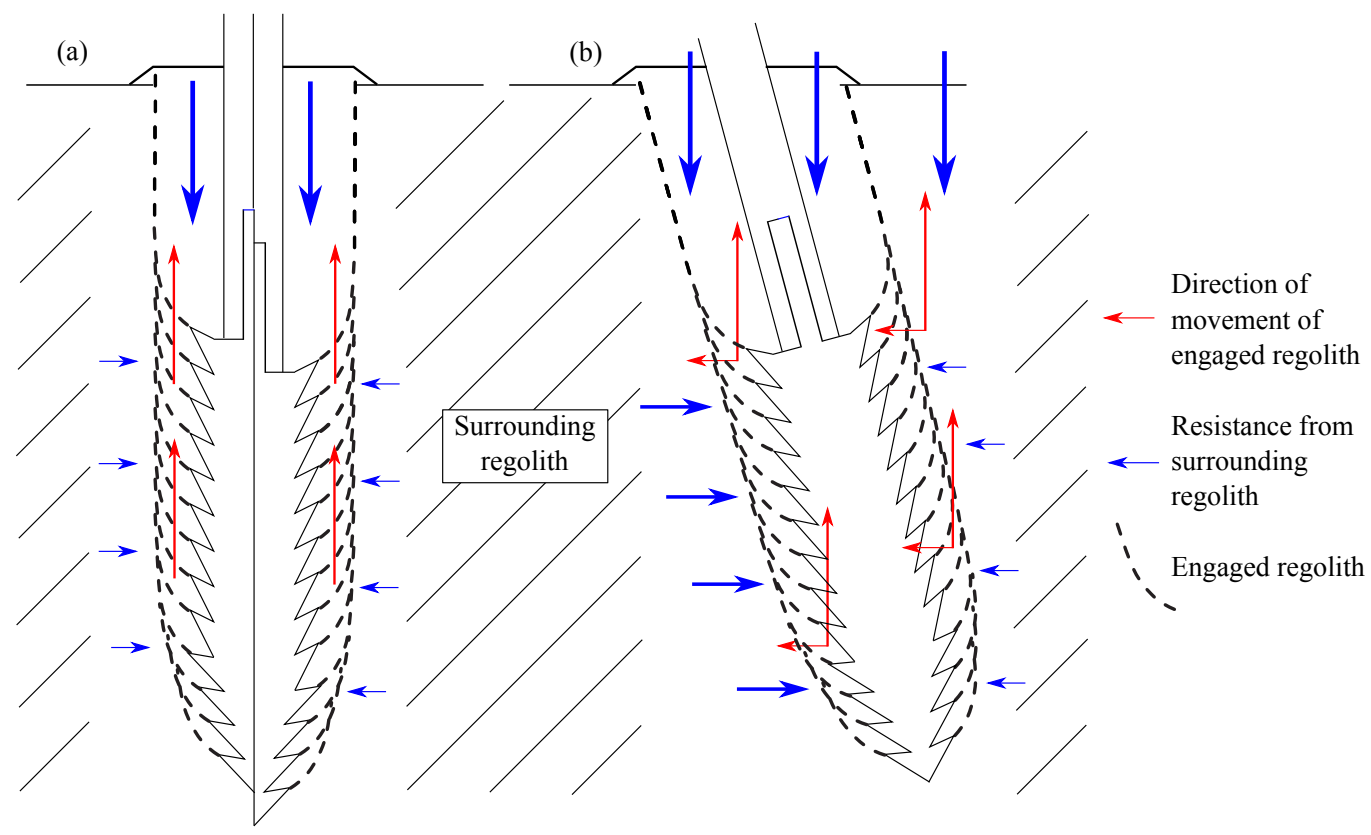

Figure 17: Compression mechanisms when drilling (a) straight and (b) at an angle

\section{Conclusions}

This paper has discussed the effects of the geometrical parameters of the DRD design on drilling performance. Drill head designs were tested in SSC-1 and SSC-2 regolith simulants using fixed operational and substrate parameters. Five key geometrical parameters were identified and assigned a high and low level, and the fractional factorial design of experiment was used to create sixteen drill heads with unique combinations of the parameter levels. The experiments were conducted using a modified set-up of the original test rig, using a new drill stem design to allow the deepest experimentation to date. These results are intended to complement the previous experiments, allowing an optimisation of the geometrical and operational parameters when designing the DRD.

The most critical parameters were found to be the radius of both the backwards-facing teeth and the drill cylinder, with the final depth achievable and total drill radius having an inverse power relationship. It was also suggested that the cone half-apex angle, which defined the shape of the cone, has a small negative linear relationship with depth. The length and angle of the teeth were believed to have a negligible effect on performance. The 
drilled substrate was shown to affect the final depth reached, but had no effect on the performance profiles given by the geometrical parameters. It was also seen that the current, and by extension power, increased linearly with depth, with the increase being larger in the denser SSC-2 regolith.

A number of experiments experienced bending of the drill stem. This often resulted in depth profiles that differed from experiments in which the drilling remained purely vertical, with significant bending causing an increase in drilling depth reached and drilling speed. This led to the consideration of the mechanics of diagonal drilling, in which the engaged regolith is pushed both horizontally and vertically. This creates an additional horizontal resistive force acting against the engaged regolith, creating a larger tensile force in the receding drill head.

The increased performance seen in the experiments that experienced bending further highlights the importance of lateral forces in the progression of the DRD. The next step in the development of the DRD should therefore be the exploration and development of internal reciprocating and lateral motion mechanisms. This will also lead to progression of the DRD from a proof-of-concept design towards a system prototype.

\section{Acknowledgements}

The authors thank OHB System AG, formerly Kayser-Threde, for providing funding for the $\mathrm{PhD}$ of which this paper will contribute to.

\section{References}

Frame, T., 2012, Evolution of a New Planetary Drill Design Using Bioinspired Dual Reciprocating Drilling Technique, In 63rd International Astronautical Congress, Naples.

Gao, Y., Ellery, A., Jaddou, M., Vincent, J. \& Eckersley, S., 2005, A Novel Penetration System for in situ Astrobiological Studies, International Journal of Advanced Robotic Systems, 2(4), 281-286.

Gao, Y., Ellery, A., Jaddou, M., Vincent, J. \& Eckersley, S., 2007a, Planetary Micro-Penetrator Concept Study with Biomimetic Drill and Sampler Design, IEEE Transactions on Aerospace and Electronic Systems, 43, 875885 . 
Gao, Y., Ellery, A., Sweeting, M. \& Vincent, J., 2007b, Bioinspired Drill for Planetary Sampling: Literature Survey, Conceptual Design, and Feasibility Study, Journal of Spacecraft and Rockets, 44(3).

Gao, Y., Frame, T. \& Pitcher, C., 2015, Piercing the Extraterrestrial Subsurface. Integrated Robotic Drill for Planetary Exploration, IEEE Robotics and Automation Magazine, 22 (1).

Gouache, T., Brunskill, C., Scott, G., Gao, Y. \& Gourinat, Y., 2010, Regolith simulant preparation methods for hardware testing, Planetary and Space Science, 58.

Gouache, T., Gao, Y., Coste, P. \& Gourinat, Y., 2009, Experimental Parametric Evaluation of Dual-Reciprocating Drilling Mechanism Performance, In European Conference on Spacecraft Structures, Materials and Mechanical Testing, Toulouse.

Gouache, T., Gao, Y., Coste, P. \& Gourinat, Y., 2011a, First experimental investigation of dual-reciprocating drilling in planetary regoliths: Proposition of penetration mechanics, Planetary and Space Science, 59.

Gouache, T., Gao, Y., Frame, T., Coste, P. \& Gourinat, Y., 2011b, Identification of the Forces Between Regolith and a Reciprocating Drill-Head: Perspectives for the Exploration of Martian Regolith, In 62nd International Astronautical Congress, Cape Town.

Hansen-Goos, H., Grott, M., Lichtenheld, R., Krause, C., Hudson, T. \& Spohn, T., 2014, Predicted Penetration Performance of the InSight $\mathrm{HP}^{3}$ Mole, In: 45th Lunar and Planetary Science Conference, Texas, USA, March.

Mitrofanov, I., Sanin, A., Boynton, W., Chin, G., Garvin, J., Golovin, D., Evans, L., Harshman, K., Kozyrev, A., Litvak, M., Malakhov, A., Mazarico, E., McClanahan, T., Milikh, G., Mokrousov, M., Nandikotkur, G., Neumann, G., Nuzhdin, I., Sagdeev, R., Shevchenko, V., Shvetsov, V., Smith, D., Starr, R., Tretyakov, V., Trombka, J., Usikov, D., Varenikov, A., Vostrukhin, A. \& Zuber, M., 2010, Hydrogen Mapping of the Lunar South Pole Using the LRO Neutron Detector Experiment LEND, Science, 330 (6003). 
Montgomery, D., 2012, Design and Analysis of Experiments, John Wiley \& Sons, 8th Edition.

Re, E., Magnani, P., Izzo, M., Rizzi, F., Senese, S., del Campo, F., Finotello, R. \& Ferrario, R., 2008, ExoMars Multi Rod Drill Development and Testing, In: 10th Workshop on Advanced Space Technologies for Robotics and Automation, Noordwijk, The Netherlands, November.

Richter, L., Coste, P., Gromov, V., Kochan, H., Nadalini, R., Ng, T., Pinna, S., Richter, H.-E. \& Yung, K., 2002, Development and testing of subsurface sampling devices for the Beagle 2 lander, Planetary and Space Science, 50.

Vaniman, D., Bish, D., Ming, D., Bristow, T., Morris, R., Blake, D., Chipera, S., Morrison, S., Treiman, A., Rampe, E., Rice, M., Achilles, C., Grotzinger, J., McLennan, S., Williams, J., Bell III, J., Newsom, H., Downs, R., Maurice, S., Sarrazin, P., Yen, A., Morookian, J., Farmer, J., Stack, K., Milliken, R., Ehlmann, B., Sumner, D., Berger, G., Crisp, J., Hurowitz, J., Anderson, R., Des Marais, D., Stolper, E., Edgett, K., Gupta, S. \& Spanovich, N., 2014, Mineralogy of a Mudstone at Yellowknife Bay, Gale Crater, Mars, Science, 343 (6169).

Vincent, J. \& King, M., 1995, The mechanism of drilling by wood wasp ovipositors, Biomimetics, 3(4), 187-201.

Weinstein-Weiss, S. \& Banerdt, B., 2013, InSight: A Geophysical Mission to Mars, In: 10th IAA Low-Cost Planetary Mission Conference, Pasadena, USA, June.

Zacny, K., 2012, Moon. Propsective Energy and Material Resources, chapter 10, Springer-Verlag Berlin Heidelberg.

Zacny, K., Bar-Cohen, Y., Brennan, M., Briggs, G., Cooper, G., Davis, K., Dolgin, B., Glaser, D., Glass, B., Gorevan, S., Guerrero, J., McKay, C., Paulsen, G., Stanley, S. \& Stoker, C., 2008, Drilling Systems for Extraterrestrial Subsurface Exploration, Astrobiology, 8(3). 